\title{
Mother tongue and education in Africa: Publicising the reality
}

\author{
Angelina N Kioko ${ }^{1 *}$, Ruth W Ndung' ${ }^{2}$, Martin C Njoroge ${ }^{2}$ and Jayne Mutiga ${ }^{3}$
}

\author{
* Correspondence: \\ andukukioko@yahoo.com \\ ${ }^{1}$ United States International \\ University, Nairobi, Kenya \\ Full list of author information is \\ available at the end of the article
}

\begin{abstract}
Varied realities surround the use of mother tongue education in Africa. These realities are entrenched in the attitudes and misconceptions that have gone unchallenged due to inadequate literature on the successful use of mother tongues in the classroom and beyond. The realities discussed in this paper include the frustrations of children introduced to education in a foreign language; misconceptions about the success of mother tongue education; educational benefits of mother tongue education; and mother tongues and enhanced economic opportunities. The foci of this paper are the success stories from Africa and the economic benefits in the use of the mother tongue in creative media or economies. These success stories are a way of getting to stakeholders to invest in mother tongue education for there are returns on such investment. The stories are also a way of challenging scholars to get out of the conference rooms and do something gainful with the mother tongues.
\end{abstract}

\section{Introduction}

Since the UNESCO land mark publication in 1953, which underscored the importance of educating children in their mother tongue, books and scholarly papers have been written on the educational significance of the choice of the language of instruction. Commissions, conventions, action plans, and charters have been put in place to promote the use of learners' first languages in education (UNESCO, 2010). Scholarly conferences have been organised to discuss research and experiments in this field, and to strategise on the way forward. These conferences, workshops and seminars have resulted in the publication of many papers and books in the subject, and, therefore, there is plenty of information on nearly every aspect of the use of the home language in education. Unfortunately a lot of this information does not seem to be reaching the people whose nod is essential for meaningful changes to take place, and perhaps when it does get to the public domain it is not packaged in the form that would communicate to this group of people.

Non-governmental organisations and other lobby groups have also produced materials to educate the public on the importance of using a child's first language in school. For example, in 2005, the Association for the Development of Education in Africa (ADEA) dedicated their April-June Newsletter to issues of Language and Education; in 2007, Save the Children produced a policy document on "The Use of Language in Children's Education" (Save the Children, 2007); in 2008, the Multilingual Education Network of Eastern Africa (MLE-N) compiled answers to the most commonly asked questions in the African multilingual context into a booklet entitled "Language and Education in

(c) 2014 Kioko et al.; licensee Springer. This is an open access article distributed under the terms of the Creative Commons Attribution License (http://creativecommons.org/licenses/by/4.0), which permits unrestricted use, distribution, and reproduction in any medium, provided the original work is properly credited. 
Africa: Answering the Questions" (Kioko et al. 2008), and distributed it internationally; and in 2010 UNESCO, UIL and ADEA put together a policy advocacy brief "Why and How Africa Should Invest in African Languages and Multilingual Education: An Evidence and Practice Based Policy Brief". Thus, there is plenty of information on why children should start education in their mother tongue. However, the key questions are: Why isn't there excitement and competition in the implementation of these findings? Why have so many declarations and policies remained on paper? The contention of this paper is that makers and movers of change are not yet convinced; the publicity of the findings of these researches have not reached the teacher, the parent, the politician, the economist, and the entrepreneur in adequate doses for them to support change. There is need for all stakeholders, language and education experts and investors to step out of conferences in large numbers and speak in the 'mother tongue' of the key stake holders.

The focus of this advocacy paper is to outline the realities that need to be broadcast in a format that can reach the child, the teacher, the parent and the official in education departments and ministries such as trade and finance.

\section{The frustrations of children introduced to education in a foreign language}

The first reality that needs to be publicised is that an education that is packaged in a language which the child does not understand is simply torture to the child. In most rural areas in Africa, children still enter school and face a foreign medium of instruction that differs from the one spoken at home despite the fact that research has consistently shown that children acquire linguistic and cognitive skills more readily in their home language. Empirical studies from both developed and developing countries show that pupils who have a home language other than the language of instruction have lower levels of attainment and achievement, and experience higher dropout rates. This is well illustrated by the findings of a survey designed to assess the achievement of learning outcomes at lower primary released by the Kenya National Examination Council (KNEC) which revealed that $52 \%$ of the Standard Three children cannot read properly and as many as $60 \%$ of them have repeated a class by the time they reach Standard Three. The problem was graver in the rural areas, where the children have little or no exposure to English outside the school setting: "Nyanza Province had the highest number of repeaters, at 69 per cent, followed by Eastern 67\%, Western 60\% and Coast 58\%" (Aduda 2010). The report rightly comments that "Reading and writing skills cut across all subjects and failure in them leads to poor mastery of others ...[and] when learners fail to master such concepts early, it becomes pretty hard for them to understand more complex ones later" (Aduda 2010). It is interesting to note that in all the newspaper coverage of this report, there was no mention of the possibility that the medium of instruction could have contributed to this; the blame was mainly attributed to the failure of parental support with a lot of blame heaped on the fathers.

Educational effectiveness requires that the content and the approach of the syllabus be focused on the needs and abilities of the learner, and that the objectives be stated in terms of the learner behaviour. But, when schooling starts in a language foreign to the learner, he or she encounters a barrier and a lot of frustration. Expecting the child to learn a new language and, at the same time base the development of literacy and other skills on this new language, is simply absurd, and goes contrary to the accepted principles of learning. When children are asked to read and write what they do not speak/understand, 
writing becomes a mysterious magical and artistic way of drawing meaningless symbols on paper: the symbols transfer from the blackboard/textbook to the learners' exercise book without a stop in their minds, and at this stage only those with pictorial minds to remember exactly how the symbols were drawn on the board will demonstrate learning. Expecting them to write and read effectively what they do not speak or understand is like asking them to run when they have not learned how to stand alone! It is like plunging the young learners without swimming skills into a fast flowing river and expecting them to make it to the other side where the teacher and the whole school system will compliment them for their success. Experience has shown that the few lucky ones get across, but the majority of them sink.

The barrier of starting school in a language that is not the learners' home language changes the focus of learning from being learner-centred to teacher-centred, and thus reinforces passiveness and silence in classrooms, which in turn suppress the young learners' potential and liberty to express themselves freely. The language handicap created by this situation dulls the excitement of the young minds, inhibits their creativity and makes the learning experience unpleasant. They neither ask questions nor seek clarifications even when they do not understand. They do not find a connection between the home and the school experiences. The frustrations encountered by learners who have to go through this system are captured in Susan Nyaga's real life narration cited below:

My little niece came home and was very excited to tell auntie how easy the test she had just done was. When I asked her to tell me some of the questions asked, she had this to say, 'one of the questions they asked us was: Jesus was crucified on a ?' I asked her what she wrote as the answer and she brought out the question paper and showed me that she had chosen the answer option ' $\mathrm{B}$ ' which had 'table' as answer, but in the mother tongue said that the answer was mutharaba which means 'cross'. I felt so sorry for her because I knew she was going to fail that question, not because she did not know the answer, but because the language of the test was an enormous barrier. I later learned that the teacher had actually read out the questions to them but she did not read the choices.

\section{Misconceptions about mother tongue and success in education}

One of the perpetuated myths about multilingualism in education is the misconception that it is unfair because some students have the L2 at the start of school. Rural parents in schools in Kenya and Uganda (Muthwii 2002) where the language in education policy requires that children start school in the home language fear that their children could be 'left behind' by children in urban contexts who start school in English. They worry that their children will not be able to compete favourably in terms of understanding what is taught in school. In a study done in Zimbabwe, Ndamba encountered the same phenomenon "parents and children had a more positive attitude towards English than the mother tongue as the language of instruction at infant level" (Ndamba 2008, p.184). According to Muthwii (2002), parents tend to be risk-averse when it comes to their children's educational futures; they do not want to experiment and thereby endanger the chances of children to succeed in school. The parents' view is that 'the child who uses English grows up understanding the subject matter better while use of the mother tongue would hamper understanding in the child" (Kioko et al. 2008, p.32). English is seen to be necessary even in Primary class 1 so that the children could be at par with other 'progressive' schools. 
Another common misconception is that the use of the home language in school hampers learning because mother tongues are not capable of communicating the complex meanings that are part of formal education. This is the fear that these languages are not equipped for use in the modern economic, technological and educational processes, but this fear is linguistically unfounded. As Kioko et al. (2008, p. 19) say:

Languages grow and change in response to changes in the physical, social, political, spiritual and economic environments in which they are used. When new objects and concepts become part of the meanings that a people have to communicate, their language will adapt to this change and incorporate expressions appropriate to the new function. Languages are able to do this through the process of borrowing lexical items or idiomatic expressions, or coining words and expressions. This is a characteristic of human language.

Languages of minority speakers are no exception to this characteristic. To many of the parents it is an issue of choice; unaware of the linguistic potential of the child, they fear that the introduction of 'too many' languages in the school system will negatively affect the learning process.

Another wrong perception concerns the link between education and enhanced economic opportunities. Many African parents make significant sacrifices to support the education of their children with the hope that the children will then qualify for good jobs and provide for the parents when they are older. Since the language of economic progress is almost invariably seen to be an official or international language, parents resist schooling in a language which they believe will inhibit their children's chances at employability after school. They see no economic value in mother tongues. In this paper it is argued that, in addition to the educational benefits, mother tongues have direct economic relevance.

The other major concern regarding the use of more than one language in education has to do with the perceived cost of such a policy. The costs of educational change are always a concern to the stakeholders, even when the costs of not changing are equally great. As Kioko et al. (2008, p. 24) point out the current cost of school failure in subSaharan Africa is immense, and much of it has to do with the choice of a language of instruction that the learners do not speak (Heugh 2004; Muthwii and Kioko 2004; Muthwii 2005; Muthwii, 2007). All school failures or drop-outs are in essence 'wasted resource' and 'wasted opportunity', whether one looks at this in terms of the individual person's loss or that of the community. It is important to note that wastage, low literacy rates, poor school performance and low achievement, together with all the social, emotional and psychological deprivations that are meted out to children who fail to learn effectively in international languages, are often underestimated when evaluating the cost of an education system. Generally, the exorbitant cost of not introducing and supporting MLE in the education systems of multilingual nations is hidden and long term.

Another commonly held misconception about language and national integration is that multilingualism, if encouraged to the extent of promoting widespread use of mother tongues, becomes a divisive force. There is, however, plenty of evidence in the literature that where national unity is at stake, the actual problem is not the existence of many languages. The many languages simply communicate animosities that stem from social, political and economic issues in the nation; this animosity could still be 
effectively communicated by use of one language, if all the nation's citizens understood it. For example, officially monolingual nations like Somalia and Rwanda have had serious internal conflicts; their single national language did not guarantee national unity for them! The culprit is not multilingualism.

\section{Benefits of mother tongue usage}

The use of mother tongues has both educational and economic benefits as discussed here below.

\section{Educational benefits}

The use of the home language in school is necessary for children to successfully make a bridge between their experiences of learning at home and learning at school. The first language that a child is exposed to and learns to express himself or herself in, is very instrumental in his or her growth in education. This language is referred to interchangeably as mother tongue or home language. Research has widely established that children whose foundation in the home language is solid will develop stronger literacy abilities in the school language, and that their knowledge and skills will easily transfer across languages (Cummins 2000). The home language helps children learn concepts and vocabulary faster, thus bringing them to quick reading and understanding skills. Mother-tongue medium learning also encourages active participation by children in the learning process because they understand what is being discussed and can effectively answer the questions posed to them. This demystifies the formal education experience, enhancing expectations of success in school, thus children became enthusiastic learners.

Research has shown that bilingualism promotes overall cognitive development, and that bilingual children demonstrate higher performance on tests of analytical reasoning, concept formation, and cognitive flexibility when their first language is maintained, the social climate is positive, and they are not negatively judged because of their language behaviour (Travers et al. 1993). Children develop confidence in using both their language and the second language for higher level thinking, rather than just repeating or memorizing what has been taught. Bilinguals who love and respect both their first language and the second language have been found to show more creativity and mental flexibility as compared to monolinguals or to those who look down on their home language (Lambert 1962).

It has been established, and is common sense, that concepts taught in the learner's home language do not have to be re-taught in a second or third language. Children will automatically transfer this knowledge to other languages as soon as they have learnt sufficient vocabulary in those languages. For example, if you teach a child in the mother tongue that seeds need soil, moisture and warmth to germinate, you do not have to reteach the child this fact in English. When the child has developed adequate vocabulary in English, he/she will translate it. Thus learning is transferable from one language to another.

The affirmation of the child's cultural identity through use of the mother tongue also has a significant impact on the way that child sees the relevance of school to his or her life. The home language thus is the best vehicle for teaching the learner's culture because the child's culture best expresses itself in the language of his or her environment. This 
way the learning is complementary to other kinds of learning that the child does outside the school environment.

The use of the home language in school also enables networking between the care givers and the teachers in the education of the child. The parents and other community stakeholders can provide support for the child far much better when they understand this process, than when they are cut off from it by a foreign language which they may not understand, as is the case in many rural African contexts.

Use of the child's home language in school can also lessen the burden on the teacher especially where the teacher speaks the local language well (which is the case in the majority of the rural schools in Africa). Research has shown that in learning situations where both the teacher and the learner are non-native users of the language of instructions, the teachers' struggles are as much as the learners', particularly at the start of education (Njoroge 2011). Thus starting teaching in a language in which the teacher is maximally fluent makes the teaching experience more natural and less stressful (Kioko et al. 2008, pp.7-8). The teacher is able to be much more creative and innovative in designing learning materials and teaching/learning approaches and, therefore, successfully obtain the learning outcomes.

In summary, the use of the learners' first language in school promotes a smooth transition between home and school, and this creates an emotional stability which translates to cognitive stability. The children thus learn better and faster, and retain the knowledge longer.

\section{Enhanced economic opportunities}

Wrong perceptions to the use of mother tongues beyond the classroom raise questions that beg answers. Could it be that stakeholders: learners, teachers, parents, curriculum developers etcetera, do not perceive the benefits of a mother tongue beyond the classroom? Many researches in English indicate that it improves chances of employment. What of the mother tongue? Does it improve chances of employment? People place value on what they consider will give them returns on investment (Heugh 2004). This view is reinforced by Foley (2007) who argues that investors in anything, language included, want palpable benefits in economic empowerment. The proceedings of the $6^{\text {th }}$ Pan African Reading for All Conference (2009) show a strong correlation between enhanced economic opportunities and investment in a language. Socio-economic variables play a very significant role in literacy learning. Such learning in turn enhances one's earning abilities.

As observed in the previous sections there is a close association between language and economic opportunities. The main misconception is that mother tongues do not give the learner a competitive edge in the national or global economy. There are no returns on investment. One of the reasons why parents and teachers continue to prefer a foreign language in education is that developing skills in mother tongue does not seem to them to be linked to economic benefits, but this is not the case; multilingualism opens opportunities to what Hesmondlalgh (2002) refers to as creative economies. Njogu and Gakuru (2009) refer to them as communication industries while Kamwangamalu (2008) calls them enhanced economic opportunities. This paper has used the terms interchangeably.

Creative economies in any language are concerned with the generation or exploitation of knowledge and information primarily for monetary value. They are not new but with 
advances in technology they are now packaged in new skins (Hesmondlalgh 2002). Eleven creative sectors have been identified and they include advertising, architecture, music, visual and performing arts, publishing, radio and television among others (DCMS 2001). The three key issues emerging from these creative sectors are that they have a potential for job and wealth creation; that they are based on the knowledge and use of a mother tongue in a multilingual setting; and that they are not hindered by restrictive language policies since they occur in contexts that are not under such controls. These three issues create a very conducive environment for those who want to use mother tongues for economic value.

Research on the creative economies indicates that there are sustainable economic opportunities if one invests in a language in multilingual contexts (Heugh and Skutnabb-Kangas 2007). The research on creative economies presented in this paper was carried out in Kenya and has mainly focused on the use of mother tongues in the media and in the informal social set ups. The research reported herein focused on an advertisement by a bank used both on the television and radio; a performing arts group that is multilingual in composition; and a dance group that is also multilingual in its composition. A questionnaire was administered to 120 respondents who were required to give their opinion of the role of the mother tongue in these three creative economies. The questionnaire focused on i) the attitude towards the use of mother tongues in the three creative economies and ii) the perceived economic opportunities in the use of mother tongues. The research factored the gender, age and education of the respondents.

The advertisement by the bank required the person involved to identify himself or herself, say what they do for a living and finish off by saying that he or she is a member of the bank (.... and I am a member). What made this statement catchy, according to the respondents, was that it was presented not only in English and Kiswahili but that it also made use of different mother tongues. Even the respondents who said they were not fluent in their mother tongues identified with the advert. They said that the advert dispelled the myth that mother tongues cannot be used for commercial purposes and that they cannot be identified with economic value.

Mother tongues are gaining currency in the advertisement world, especially on radio and television (Oriare et al. 2010). Many radio listeners prefer local language radio stations to English or Kiswahili ones because they can identify with the language and the local content. An interesting observation is that about $71 \%$ percent of those who listen to the local language radio stations are youths aged between 15-34 years (Oriare et.al. 2010). Going by this one can conclude that there is a large market for the mother tongue in the local media stations. The use of mother tongue has both sustainability and continuity (Njogu and Gakuru 2009).

Performing groups are also a prominent feature of the creative economies in Kenya. Their brand is the ability to travel from one venue to the other to entertain guests during events such as weddings, fund raisings and marriage negotiation ceremonies. Research findings indicate that the popularity of performing groups is tied to their ability to communicate in different languages. The group have what is referred to as etic - the outsider information as well as emic - the insider description of language and culture according to Agar (2010). The performing groups also owe their popularity to the use of interactive performances. For instance, members of the audience could be called upon to say 
something or even to do something as part of the entertainment. This requires quick thinking or having the knowledge and information required at the finger tips (Hesmondlalgh 2002). The ingenuity of the performances makes them new every occasion. What is produced is meant to be consumed in that particular place and at that particular moment. According to Caves (2000), consumers care about originality, technical and professional skills in the productions. The fact that the performances are not duplicable means that consumers have to keep on asking for more. This creates a ready market for the performances making the sector a self sustaining one.

The performers do not use any script, which makes their performances very situational. They make an effort to learn the language and the culture relevant to the occasion. To exploit the multilingual Kenyan context for monetary gain, they have invested in learning the languages and cultures of different catchment areas. They have also invested in representative performers from different languages. To do this, they have had to deal with what Crawford (2007) refers to as the myths and prejudices of use of mother tongue. One such myth is that the mother tongue does not enhance economic opportunities.

Africans are known for their love of dance and song. Every occasion calls for a song and the accompanying dance: be it birth, marriage, graduation or death. Dance groups have become a common feature in many events. Often such groups, like the one focused on in this research, are made up of members from different language communities. The dance groups are hired to dance during different occasion, especially weddings. The research findings indicate that successful groups in Kenya have popularized tunes from different communities because of the way they perform them with pride and dignity. They draw content from the folklore of the different Kenyan communities. They perform dances from different communities that have been passed on from one generation to the other with few or no adaptations. What makes their dances unique, however, is the way they package mother tongue meanings to make them attractive to the audience. The repackaging is referred to as 'infinite variety' by Caves (2000) who explains that products are differentiated by their quality and uniqueness. In this way, the dance groups have succeeded in repackaging mother tongue for higher economic value.

The three creative economies that were surveyed have exploited the capacity to make meaning in specific situations and turned mother tongues into a commodity that they have sold to different consumers. A negative attitude towards knowledge of a mother tongue or its use would miss out on this opportunity.

Mother tongues are the foundation of the culture that is exploited in the creative economies (Kristeva 2010). The mother tongues provide not only the language but the socio-cultural practices that go into performance art and dance. It is, therefore, essential to ground the knowledge of a mother tongue in the knowledge of the culture that it is embedded in. Any community that wants to exploit the mother tongues in creative economies must of necessity view the mother tongues positively. According to Deane (2006), people want to make informed choices regarding their mother tongues. They want to make use of their mother tongues not only for education but also for the transmission of social change, persuasion, entertainment and mobilization.

\section{The way forward in publicizing the reality}

Success stories in the use of mother tongue in education in Africa are many but they have not been well publicized. How will stakeholders make informed choices if they are 
not aware of the truth on the ground? The use of different mother tongues must not be seen as a divisive factor in the classroom or beyond. Instead it should be viewed as an opportunity to enhance learning and economic opportunities. Success in the use of the mother tongue must, therefore, be explored and documented in and beyond the classroom.

New technologies have made access to mother tongues extensive. Such access is seen to be coupled with enhanced learning and economic opportunities. These are the opportunities, according to Oriare et al. (2010), that present business interests that must be exploited.

\section{Conclusion}

The paper has pointed out the need to rethink the place of mother tongues in education and beyond. Evidence supports the benefits of mother tongue in early childhood education and particularly in the achievement of Education for All. For mother tongues to be revitalized, all must be willing to change their attitude towards the same. One's own mother tongue is one's identity and it should not in any way be denigrated. In fact, there are benefits when one starts looking at the world from his or her own perspective instead of looking at it from the colonial perspective. Africa should look at the languages spoken by the citizens in terms of how they can be utilized to contribute to the welfare of the citizens as it is in preparing these languages for enhanced gainful utilization that they get developed.

The mother tongues in Africa need to be revitalized and used in all spheres of life because they are "our languages, our culture, our gift and pillar for Africa's development" (Zombe 2008). Exposing these languages to the citizenry will help bring up a people who are skilled, creative, and great problem solvers; consequently, bringing up development in Africa. Indeed Africa must be ready to use her diverse tongues to tell her story and explain herself to the world. As Fanon, cited in Caute (1970), concludes, for the African masses to participate in national development, they must first of all be able to tell their story in their own tongues. But this calls for the political commitment of the national leaders in Africa if meaningful strides are to be made for the integration and recognition of indigenous languages in education, first in Africa and then globally.

Approaches that rely on local languages alone or maintain them as tools and subjects of instruction are somewhat rare. Yet, research indicates that the use of languages actually spoken by learners as instructional languages leads to increased efficiency, fewer dropouts and repetitions, improved learning outcomes and to top it all, a good command of the major international language of communication. The current apathy in the use of mother tongues has often been blamed on lack of political will, lack of technical skill and resistance on the part of parents and learners. Erroneously so, this study seems to indicate. We must stop pointing the finger at policy-makers and take another look at the role of education specialists and other advisors, without blaming them and without assigning them full or primary responsibility for the foot-dragging on this issue. We must be critical, but not to the point of self-flagellation. No single group bears full responsibility for the current state of affairs, and there is a need to review the arguments and to question current approaches while recognizing that great progress has been made. The reality is that mother tongues are making a mark in the classroom and in the economy. 


\section{Competing interests}

The authors declare that they have no competing interests.

\section{Authors' contributions}

The authors worked together to come up with the outline of the sections of the paper, and distributed the research and drafting tasks. All the authors also participated in the writing of the 'The Way Forward in Publicizing the Reality', and the 'Conclusion' sections of the paper. The individual authors researched, drafted and performed other tasks as outlined below: Prof. ANK. Researched and drafted the introduction of the paper. Researched and drafted The Frustrations of Children Introduced to Education in a Foreign Language' section. Jointly researched and drafted 'Misconceptions about Mother Tongue and Success in Education' section. Compiled the first complete draft of the paper. Dr. MN. Researched and drafted 'Educational Benefits' section. Coordinated response to reviewers' comments. Incorporated the necessary revisions. Dr. RN. Researched and drafted the 'Enhanced Economic Opportunities' section. Coordinated response to reviewers' comments. Incorporated the necessary revisions. Prof. JM. Jointly researched and drafted 'Misconceptions about Mother Tongue and Success in Education' section. All authors read and approved the final manuscript.

\section{Authors' information}

Angelina Nduku Kioko is a Professor of English and Linguistics at the United States International University - Africa. Her interests and publications are in syntax, morphophonology, sociolinguistics and language learning materials. Her current research interests are in the field of language and education in multilingual contexts.

Ruth W. Ndung'u is a senior lecturer of English language and linguistics, Kenyatta University, Kenya. She has carried out extensive research on second language education and the use of language and published for the secondary and tertiary institutes. She is an advocate of the use of mother tongue education in early childhood education and a member of the Multilingual Education Network, Kenya.

Martin C. Njoroge is a senior lecturer of Linguistics and Director of Confucius Institute at Kenyatta University, Kenya. He has published widely on multilingual education, second language acquisition, and sociolinguistics, language in education issues, language variation and general linguistics. He is a former SRF postdoctoral fellow at the University of Pennsylvania, USA, and a member of the Multilingual Education Network, Kenya.

Jayne Mutiga is an Associate Professor of Linguistics and Communication at the University of Nairobi. She is widely published in phonology and sociolinguistics. Her current research interests are in multilingualism and mother tongue education as well as language planning, linguistic human rights and language endangerment and documentation. Prof. Mutiga is a member of the Multilingual Education Network, Kenya.

\section{Acknowledgements}

The authors would like to first acknowledge the inspiring partnership in the Multilingual Education Network (MLEN) in Kenya, and especially the steering committee of MLEN for putting together forums where members get opportunities to team up for presentation and publication. We also express our gratitude to the organizing committee of the Multilingualism and Education: Global Practices, Challenges and the Way Forward' at Kenyatta University for according us a forum to share the initial thoughts articulated in this paper. The feedback we received after the presentation helped to shape the final draft.

\section{Author details}

${ }^{1}$ United States International University, Nairobi, Kenya. ${ }^{2}$ Kenyatta University, Nairobi, Kenya. ${ }^{3}$ University of Nairobi, Nairobi, Kenya.

Received: 21 February 2014 Accepted: 15 July 2014

Published: 31 July 2014

\section{References}

ADEA Newsletter. 2005. Vol.17 No.2. Theme: Education and Languages. http://www.adeanet.org/portalv2/en/content/ adea-newsletter-vol17-no-2-april-june-2005\#.U-U_bzHfrlU.

Aduda, D. 2010. Kenyan Schools: Disaster in Making. Daily Nation.

Agar, N. 2010. Humanity's End: Why We should Reject Radical Enhancements. Cambridge MA: MIT Press.

Caute, D. 1970. Frantz Fanon. New York: Viking.

Caves, R. 2000. From Cultural to Creative Industries: Theory, Industry and Policy Implications. Cambridge, Mass: Havard University Press.

Crawford, J. 2007. A Diminished Vision of Civil Rights: No Child Left Behind and the Growing Divide in how Education Equity is Understood. Education Week June 6: 2007.

Cummins, JG. 2000. Language, Power and Pedagogy: Bilingual Children in the Crossfire. Clevedon: Multilingual Matters Ltd.

DCMS. 2001. Department of Culture, Media and Sport, Libraries, Information and Archives Division: Comprehensive, Efficient and Modern Public Libraries Standards and Assessment. London: DCMS.

Deane, M. 2006. Achieving Development Goals through Cost-effective Open and Distance Learning in Sub-Saharan Africa: What costs, how effective?.. Conference paper, available online: http://pcf4.dec.uwi.edu/viewpaper.php? $\mathrm{id}=275$ \&print $=1$ accessed 30 June 2012.

Foley, A. 2007. Mother Tongue Education in South Africa. English and Multilingualism in South African Society. Papers from the English National Language body of PanSALB. 2 February 2007.

Hesmondlalgh, DJ. 2002. Defining the Creative Economy: Industry and Occupational Approaches. London: Sage Periodicals Press.

Heugh, K. 2004. Is Multilingual Education Really more Expensive? In Making Multilingual Education a Reality for All: Operationalizing Good Intentions (pp.212-233). (Proceedings of 3rd International Conference of DALEST and 1st Malawian Language Symposium, Mangochi, Malawi, 30 August - 03 September, 2003), ed. JF Pfaffe. Zomba: Centre for Language Studies. 
Heugh, K, and T Skutnabb-Kangas. 2007. Education for All in the Multilingual World- Is this Feasible? Paper presented at the annual Comparative and International Education Society (CIES) Conference, 25 February-1 March, in Baltimore, Maryland.

Kamwangamalu, N. 2008. Commentary from an African and International Perspective. In Can Schools Save Indigenous Languages? Policy and Practice on Four Continents, ed. NH Hornberger, 136-151. New York: Palgrave Macmillan.

Kioko, A, J Mutiga, M Muthwii, L Schroeder, H Inyega, and B Trudell. 2008. Language and Education in Africa: Answering the Questions. Nairobi: UNESCO.

Kristeva, J. 2010. Narration et Transformation Semiotica, 1(4), Published online 01/03/2012.

Lambert, WE. 1962. Interlingual Interference in a Bilingual Version of the Stroop Color-word Task. Montreal, Canada: McGill University.

Muthwii, MJ. 2002. Language Policy and Practices in Education in Kenya and Uganda. Nairobi: Phoenix Publishers.

Muthwii, MJ. 2005. Working with Discouraged Languages: A Broad Approach to Literacy Challenges in Africa. Current Trends in Scripture Translation: Definitions and Identity. Bulletin No. 198/199, (pp. 239-256). Reading: United Bible Societies.

Muthwii, MJ. 2007. Language Planning and Literacy in Kenya: Living with Unresolved Paradoxes. In Language Planning and Policy: Issues in Language Planning and Literacy, ed. A Liddicoat, 46-62. Clevedon: Multilingual Matters Ltd.

Muthwii, MJ, and AN Kioko (eds.). 2004. New Language Bearings in Africa. Clevedon: Multilingual Matters Ltd.

Ndamba, GT. 2008. Mother Tongue Usage in Learning: An Examination of Language Preferences in Zimbabwe. The Journal of Pan African Studies 2:4.

Njogu, K, and A Gakuru. 2009. New Communication Technologies and Freedom of Expression in Kenya: A Report from the Freedom of Expression Project. Kenya: Twaweza Communication.

Njoroge, MC. 2011. Linguistic Variation in a Multilingual Setting: Evidence from Kenya, Africa. Staarbrucken: VDM Verlag Publishers.

Oriare, P, R Okello-Orlale, and W Ugangu. 2010. The Media We Want: The Kenya Media Vulnerabilities Study. Nairobi: Friedrich Ebert Stiftung FES.

Save the Children. 2007. The Use of Language in Children's Education: A Policy Statement. http://www.savethechildren. org.uk/resources/online-library/the-use-of-language-in-childrens-education-a-policy-statement.

2009. The 6th Pan African Reading for All Conference. http://www.sil.org/sil/news/2009/pan-african-reading-conference.htm.

Travers, J, SN Elliott, and TR Kratochwill. 1993. Educational Psychology: Effective Teaching, Effective Learning. Oxford: Brown and Benchmark.

UNESCO. 1953. The Use of Vernacular Languages in Education. Paris: UNESCO.

UNESCO. 2010. Educational for All: Global Monitoring Report. Paris: UNESCO.

Zombe, G. 2008. English vs Kiswahili: Tanzania at Crossroads. Available: http://www.africanexecutive.com/modules/ magazine/article_print.php?article=2560. Retrieved September 20, 2012.

doi:10.1186/s13616-014-0018-x

Cite this article as: Kioko et al: Mother tongue and education in Africa: Publicising the reality. Multilingual Education 2014 4:18.

\section{Submit your manuscript to a SpringerOpen ${ }^{\circ}$ journal and benefit from:}

- Convenient online submission

- Rigorous peer review

- Immediate publication on acceptance

- Open access: articles freely available online

- High visibility within the field

- Retaining the copyright to your article

Submit your next manuscript at $\boldsymbol{\nabla}$ springeropen.com 